\title{
DEVELOPMENT, HOST PREFERENCE AND LEAF CONSUMPTION OF THE LIME SWALLOW TAIL BUTTERFLY, PAPILIO POLYTES ROMULUS CRAMER (PAPILIONIDAE: LEPIDOPTERA) ON CITRUS
}

\author{
M.M.H. KHAN*, M.N. MOLLA AND M.A. RAHMAN \\ Department of Entomology, Patuakhali Science and Technology University, \\ Dumki, Patuakhali-8602, Bangladesh
}

\begin{abstract}
Studies were conducted to know the developmental period and host preference of the lime swallow tail butterfly, Papilio polytes romulus Cramer and leaf consumption by its larvae on citrus in the laboratory. Ten Citrus host plants such as Kagoji lime-BAU-1, BAU-2, BAU-3, BAU-4, BARI kagoji, elachi lime, sweet orange, orange, jamir and Pumelo were used as study materials. Results revealed that the most preferred host of Papilio polytes romulus L. was Elachi followed by BAU-3 and Orange while the least preferred host was Pumelo. Eggs were pale yellow and spherical. The average length of newly hatched caterpillars, 2nd, 3rd, 4th and 5th instar larvae were $2.32 \mathrm{~mm}, 10.75 \mathrm{~mm}$, $14.50 \mathrm{~mm}, 24.80 \mathrm{~mm}$ and $39.50 \mathrm{~mm}$, respectively. The mean duration of 1st, 2nd, 3rd, 4th, 5th instar larvae and pre-pupa were 2.20, 2.15, 2.35, 2.25, 2.35 and 1.0 days, respectively. The average length of the pupal stage, adult male and female butterfly were $29.50,24.00$ and $25.75 \mathrm{~mm}$, respectively. The mean longevity of female and male was 6.5 and 3.9 days. The percentage of leaf area consumed was increased with increasing the age of larvae. The highest percentage of leaf area was consumed by the 5th instar larva (100) followed by 4th instar (75) while the lowest percentage of leaf area was consumed by the $1^{\text {st }}$ instar larva (15) in 72 hours after release.
\end{abstract}

Key words: Lime swallow tail butterfly, Development, Host preference, Leaf consumption, Citrus

\section{Introduction}

Citrus crop posses great adaptability to various climatic conditions and hence grown equally both in tropical and subtropical regions as well as some favourable parts of the temperate regions of the world. It stands in second position in the world and third among all subtropical fruits (Samson 1986). In Bangladesh citrus crop covers an area of about 5786 acres with an annual production of $68721 \mathrm{M}$ tonnes (BBS 2016). The yield of citrus in Bangladesh is very low compared to other countries due to insect pests, diseases and planting of low yielding varieties. Citrus is attacked by a large number of insect pests which cause decline in yield (Chadha 1970). About 823 species of insects and mites attack citrus trees in the world (Ebeling 1959). Among the various insect pests that attack citrus, a few are pests of major importance, namely lemon butterflies, swallow tail

*Author for correspondence: <mohasin1965@pstu.ac.bd>. 
butterfly, citrus leaf miner, citrus psylla, whiteflies, scale insects and mealybugs. Papilio polytes romulus Cramer, the lime swallow tail, is one of the most common and wide spread members of the family Papilionidae. It is also known as the common mormon, lime swallow tail, citrus swallow tail or chequered swallow tail and is found throughout Southern Asia. It is widely distributed from Farmosa to Arabia including Burma, Bangladesh, Ceylon, India and Pakistan (Butani 1973). It is a regular pest in nurseries, young seedlings, and on new flush of full grown up trees. Pest activity was severe during October to December (Lakshminarayanamma 2000). Most of the Papilio species reported till now preferably feed on various plants of Rutaceae family with special preference towards both wild and cultivated species of Citrus. Papilio polytes romulus attacks only the younger and tender leaves of the new flushes. Severe infestation results in defoliation of the tree (Bhutani and Jotwani 1975) and leads to retarded plant growth and decreases fruit yield (Pruthi 1969). For proper management of any insect pest, it is important to know the developmental strategy, morphometrics and feeding behavior of the insect. The sufficient information regarding development strategy, morphometrics and feeding behavior of the lime swallow tail butterfly is very scanty in Bangladesh.

The study includes parameters such as duration of life stages, morphometrics, host preference and leaf consumption of this insect. Therefore, the present research program was undertaken to know the developmental period and host preference of different immature stages of the lime swallow tail butterfly and leaf consumption by the larvae of this insect.

\section{Materials and Methods}

Studies were conducted in the laboratory, Department of Entomology, Patuakhali Science and Technology University (PSTU), Dumki, Patuakhali, Bangladesh during October to December, 2016. The eggs and larvae of Papilio polytes romulus were collected from citrus trees of the campus of PSTU on October, 2016. The collected larvae were reared on citrus leaves in the laboratory condition at $25.2-26.5^{\circ} \mathrm{C}$ room temperature, $71-80 \%$ relative humidity, and a photoperiod of L12 : D12, until adult emergence. To observe the development of the adult butterflies for the study, different stages of the larvae available were collected from lemon plants of the university campus. They were placed singly on 10 Petri dishes (15 cm diameter) with young lemon leaves (variety BARI Kagoji lime, Citrus aurantiifolia Swingle). Those 10 Petri dishes were used as 10 replicates. The leaves were supplied as food for the larvae and were changed every 24 hours interval. Water soacked cotton ball was used around petiole to keep the leaves fresh. The durations 
and the number of moultings of each larval instar were noted. The larval instars were determined by the presence of exuviae. As they reached final instar, the larvae were placed on twigs of lemon plants. Finally, those were set in 10 glass jars $(14 \mathrm{~cm} \times 8 \mathrm{~cm})$ to assist in pupation. The base of the twig was set in a narrow mouthed bottle filled with water to keep that fresh. Days required for the completion of the pupal stages were also recorded. When the adults emerged, the longevity of adult was recorded.

The study was carried out in a free choice test. Ten Citrus host plants, such as BAU-1, BAU-2, BAU-3, BAU-4, BARI Kaghzi (Citrus aurantiifolia Swingle var. Kaghzi lime), elachi lime (Citrus aurantiifolia), sweet orange or malta (Citrus sinensis L. var. Washington Navel), orange (Poncirus trifolia or Citrus aurantium L. var. Khatta), Jamir (Citrus assamensis) and Pumelo (Citrus grandis) were selected from the germplasm centre of PSTU for this study. Ten leaves of 10 different citrus host plants were randomly selected and collected. The collected leaves were placed in a wooden box measuring 50 $\mathrm{cm} \times 40 \mathrm{~cm} \times 5.5 \mathrm{~cm}$ with glass lid maintaining equal distances among all leaves. The larvae of lime swallow tail lime butterfly were released in a central point of box. The preference of host leaves by the larvae were observed and recorded at $24 \mathrm{hrs}$ after release. The percentage of leaf area feeding was measured by eye estimation.

Different larval stages were used in this experiment. Preliminary studies were conducted to determine the area (\%) of leaves consumed by each larval stage in 24,48 and 72 hours after release (HAR). The leaves were collected from the respective plants and the end part of their petiole was wrapped with moistened cotton to prevent dehydration prior to placing them in the Petri dish. Thereafter, the larvae starved for $4-5 \mathrm{hrs}$ were introduced to each Petri dish containing the respective combination of leaves and allowed to feed on the leaves for $24 \mathrm{hrs}$ period. All larval instars were fed with leaves from elachi lime in no choice test in Petri dishes $(15 \mathrm{~cm})$.

\section{Results and Discussion}

A. Developmental stages of lime swallow tail butterfly egg: The eggs of the common mormon are laid singly on young stem, petiole or underside of the leaves of the host plants. The egg is pale creamy yellow with a finely roughened surface. It is nearly spherical with a diameter from 1.0 to $1.2 \mathrm{~mm}$ (Plate 1), but became dark as the larva developed within. The egg takes about three days to mature. Radke and Kandalkar (1988) stated that spherical and pale yellow eggs are laid singly on the upper surface of young leaves. These darken as the larva develops within, and hatch after 5 - 9 days. A single female laid 15 - 22 eggs. 
Larval development: There were only five larval instars of the butterfly which totally lasted for 8.70 to 13.90 days. The average duration of first to fifth instars was 2.20, 2.15, $2.35,2.25$ and 2.35 days, respectively (Table 1 ).
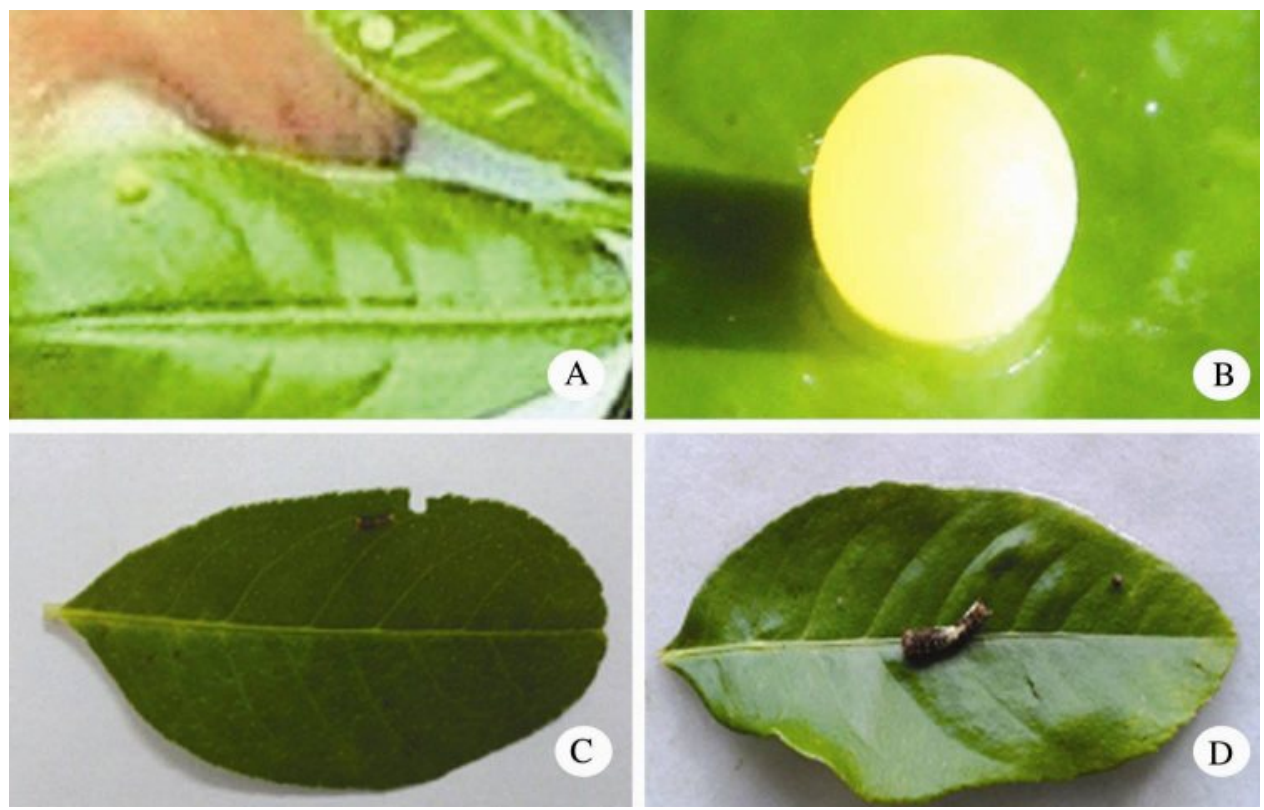

Plate 1. Egg (A - normal size; B - enlarged form), 1st (C) and 2nd (D) instar larval stages of the lime swallow tail butterfly.

Table 1. Duration of different life stages of the lime swallow tail butterfly.

\begin{tabular}{|c|c|c|}
\hline \multirow{2}{*}{$\begin{array}{l}\text { Developmental } \\
\text { stage }\end{array}$} & \multicolumn{2}{|c|}{ Duration (Days) } \\
\hline & Range & Mean \\
\hline 1st instar larva & $1.8-2.6$ & 2.20 \\
\hline 2nd " & $1.6-2.7$ & 2.15 \\
\hline 3 rd " & $1.8-2.9$ & 2.35 \\
\hline 4 th " & $1.7-2.8$ & 2.25 \\
\hline 5 th " & $1.8-2.9$ & 2.35 \\
\hline Prepupa & $1.0-1.0$ & 1.0 \\
\hline Pupa & $13-14$ & 13.5 \\
\hline Adult longevity male & $3.6-4.2$ & 3.9 \\
\hline Adult longevity female & $6.0-7.0$ & 6.50 \\
\hline
\end{tabular}

First instar larva: Newly hatched caterpillars were less spiny, cylindrical in shape, light brown to brownish black in colour with thorax thicker than rest of the body having dirty white mark on dorsal side showing resemblance to bird's excreta (Plate 1). The length 
and width of newly hatched caterpillar on an average measured 2.32 and $0.44 \mathrm{~mm}$, respectively. The average length, width at middle, and posterior points of the first instar larva were 5.50, 2.00 and $1.00 \mathrm{~mm}$, respectively (Table 2). The average duration of the first instar larva was 2.20 days with the range of 1.80 to 2.60 days (Table 1 ). The findings regarding the $1^{\text {st }}$ instar larvae were in agreement with the reports of Resham et al. (1986) and Maheswarababu (1988).

Table 2. Morphometrics of immature stages, adult and wing expansion of the lime swallow tail butterfly.

\begin{tabular}{lccc}
\hline \multirow{2}{*}{$\begin{array}{l}\text { Stages and } \\
\text { appendage }\end{array}$} & \multicolumn{3}{c}{ Size $(\mathrm{mm})$} \\
\cline { 2 - 4 } & Length & \multicolumn{2}{c}{ Width } \\
\cline { 2 - 4 } & & 2.00 & Middle \\
\hline 1st instar larva & 5.50 & 2.92 & 1.00 \\
2nd " & 10.75 & 3.50 & 3.00 \\
3rd " & 14.50 & 5.13 & 3.75 \\
4th " & 24.80 & 7.20 & 6.00 \\
5th " & 39.50 & 7.65 & 6.25 \\
Pre-pupa & 27.72 & 8.00 & 5.63 \\
Pupa & 29.50 & 4.00 & 2.50 \\
Adult male & 24.00 & 5.75 & 3.00 \\
Adult female & 25.75 & 24.00 & - \\
Fore wing expansion & 37.50 & 23.00 & - \\
Hindwing expansion & 28.50 & & \\
\hline
\end{tabular}

Second instar larva: The second instar larvae were less spiny and dark brown in colour with a dirty white line present obliquely along lateral sides of the abdomen and with a break on the dorsal side. A horn-like structure was present on the dorsal side of the last body segment (Plate 1). The average size of the second instar larvae in length, width at middle and posterior points was $10.75,2.92$ and $1.58 \mathrm{~mm}$, respectively (Table 2). The average second instar larval period was 2.15 days with a range from 1.60 to 2.70 days (Table 1). These results differ with the observations made by Ganguli and Ghosh (1967) recording 7.00 and $2.00 \mathrm{~mm}$ in length and width, respectively. This deviation might be due to differences in climatic factors and also due to seasonal variations from year to year.

Third instar larva: The third instar larvae resembled the second instar larvae except in size (Plate 2). The average length, width at middle, and posterior points of the third instar larvae were $14.50,3.50$ and $3.00 \mathrm{~mm}$, respectively (Table 2). The average third instar larval period was 2.35 days with range from 1.80 to 2.90 days (Table 1). Similar observations were also reported by Maheswarababu (1988) and Asokan (1997). 
Fourth instar larva: The fourth instar larvae were black in colour with a little greenish tinge and whitish bands could be seen on meso and meta thoracic segments laterally, anterior part of abdomen and on last anal segments. Two red coloured sacs or osmeteria opening in the first thoracic segment were observed dorsally at the anterior portion (Plate 2). The average size of the fourth instar was $24.80 \mathrm{~mm}$ in length, $5.13 \mathrm{~mm}$ in width at middle and $3.75 \mathrm{~mm}$ in width at posterior points (Table 2). The average fourth instar larval period was 2.25 days with a range from 1.70 to 2.80 days (Table 1 ).

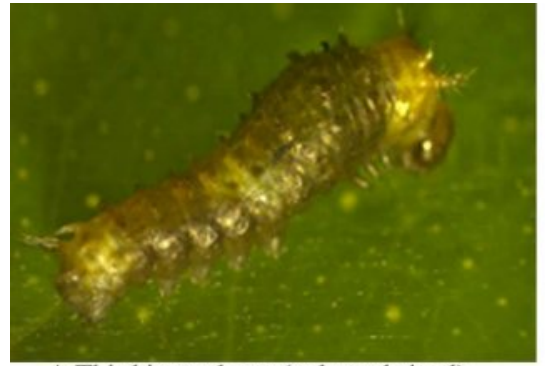

A.Third instar larva (enlarged sized)

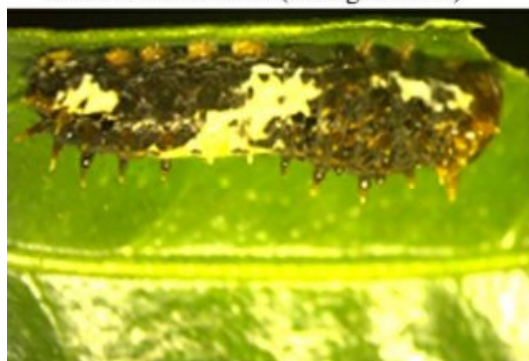

C. Fourth instar larva (enlarged sized)

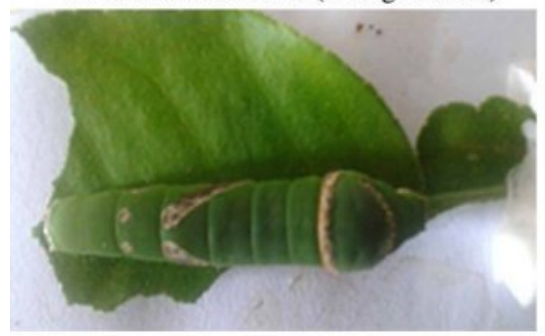

E. Fifth instar larva

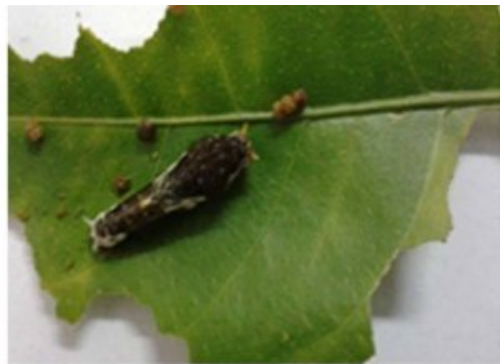

B.Third instar larva (normal sized)

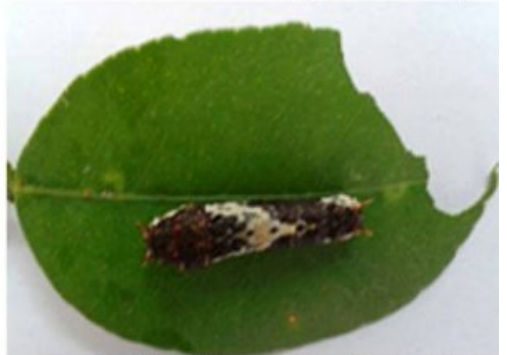

D. Fourth instar larva (normal sizer

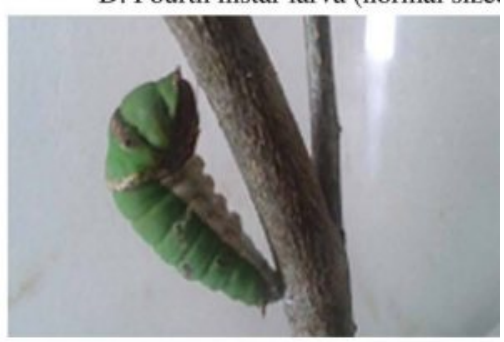

F. Pre-pupa

Plate 2. The 3rd (A\&B), 4th (C\&D), 5th (E) instar larval and pre-pupal (F) stages of the lime swallow tail butterfly.

Fifth instar larva: The fifth instar larvae were yellowish green or green in colour. Brownish stripes present on eighth and ninth sternites with two semi circular yellowish 
bands on elevated portion of the body. Two eye-like spots were present on second thoracic segment and a horn like structure was found on the dorsal side of the last body segment (Plate 2). The average length, width at middle and posterior points of the fifth instar larva were 39.50, 7.20 and $6.00 \mathrm{~mm}$, respectively (Table 2). The average duration of the fifth instar larva was 2.35 days with a range from 1.80 to 2.90 days (Table 1 ). The fourth and fifth instar larvae both had an osmeterial gland in the first thoracic segment and this organ was defensive in function. These descriptions were in agreement with Leslie and Berenbaum (1990) who reported that secretions produced by osmeterium contained iso-butyric acid, 2-methyl butyric acid and small quantities of methyl and ethyl esters.

In the present study there are five larval instars, similar to that reported by Mushtaque (1964), but differing slightly from Badawi (1981) who reported 5 - 6 larval instars. In our study the duration of the larval stage ( 8.70 - 13.90 days) was found to be shorter than ranges reported in the literature, specifically 13 - 26 days by Mishra and Pandey (1965), 18 - 25 days by Sharifi and Zarea (1970), 11 - 31 days by Badawi (1981), 16 days (Rafi et al. 1989) and 11 - 30 days by Rafi et al. (1999b). The longer periods were reflective of cool-weather larval development. Corbet and Pendlebury (1992) stated that at this stage the mature larvae suffer heavy mortality. The larvae of this species can often be found in the company of the larvae of Papilio polytes and P. memnon, which are very similar in appearance. The larval stage generally lasts 15 - 26 days, depending on temperature. These observations regarding pre-pupa were in conformity with Maheswarababu (1988) and Asokan (1997), Resham et al. (1986).

Pre-pupa: Before changing to pre-pupa the caterpillar shrunk inside and it hangs from the twig with the help of a silken girdle (Plate 2). These were in agreement with Atwal (1964). The pre-pupal period was observed lasted for one day (Table 1). The average prepupal length, width at middle, and posterior end was 27.72, 7.65 and $6.25 \mathrm{~mm}$, respectively (Table 2).

Pupa: Pupation takes place a day later. The pupa suspends itself with a silk girdle from the stem. Pupae were naked and varied in colour from green, straw to brown majority being green in colour with several black markings on the body. The pupa was initially green in colour and at the time of adult emergence it turned to light brown to brown colour. In the green form, the pupa is mainly green with a large yellowish diamondshaped on the dorsum of the abdominal segments. In the brown form, the pupa is manly greyish to darker shades of brown. After 8 days of development, the pupa turns black as the development within the pupal case comes to an end. The next day the adult butterfly 
emerges from the pupal case. The wings and abdomen of the adult inside the pupal case were clearly seen at the end of the pupal stage (Plate 3). The average length, width at middle, and posterior points of the pupal stage were 9.50, 8.00 and $5.63 \mathrm{~mm}$, respectively (Table 2). These were in conformity with the observations of Atwal (1964) and Resham et al. (1986). The duration of the pupal period was on an average of 13.50 days (Table 1). Ganguli and Ghosh (1967), Sharifi and Zarea (1970) and Radke and Kandalkar (1988) observed similar trends in the duration of pupa.

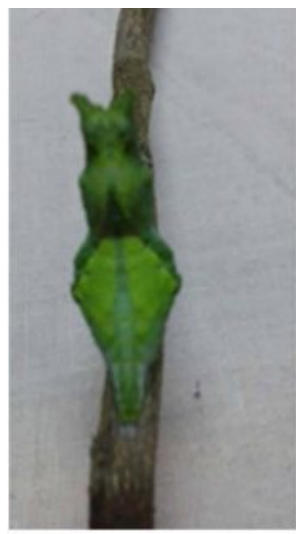

A-Green pupa

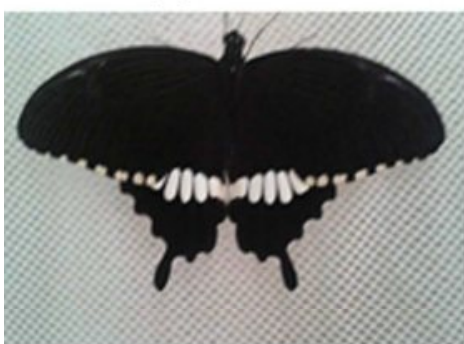

D-Male

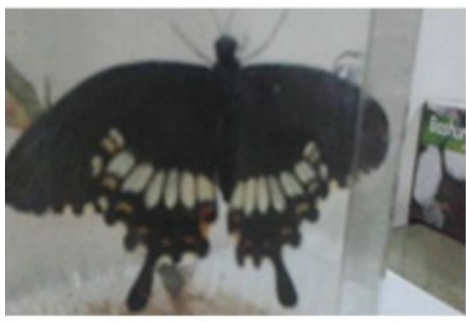

F-Female

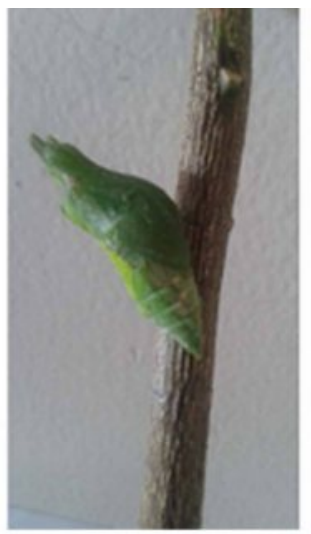

B-Green pupa

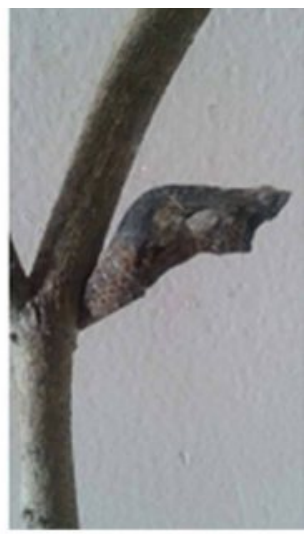

C- Brown pupa

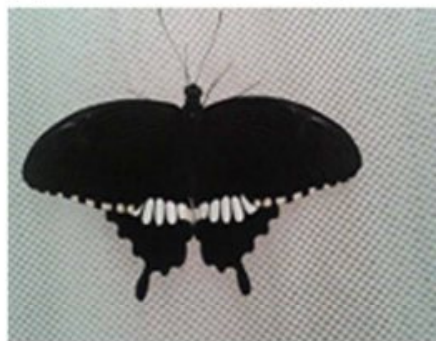

E-Male

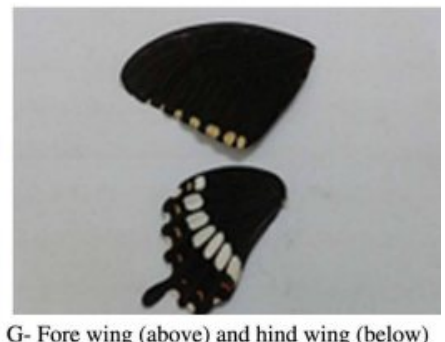

G- Fore wing (above) and hind wing (below)

Plate 3. Pupal (A-C) and adult stages (D-F), wings (G) of the lime swallow tail butterfly, $P$. polytes romulus. 
The length of the pupal stage was 13 - 14 days which is similar or dissimilar to the reports published in the literature, specifically 18 days in Rafi et al. (1989), 7 - 21 days in Rafi et al. (1999b), 11.7 days in Badawi (1981), and 9.4 - 12.2 days in Sharifi and Zarea (1970). Sharifi and Zarea (1970) reported that the pupal stage of $P$. demoleus is very sensitive to temperature undergoing diapause in winter, any rise in temperature above $25^{\circ} \mathrm{C}$ caused the adult emergence from the pupae. The same results were observed during the present study. Talbot (1939) reported that greenish pupal color was due to pupal development in proximity to leaves or any other green object, and brown pupal color was due to proximity to brown objects. Our observations support these findings. Tauber et al. (1986) reported that pupal polymorphism does not affect rate of development of the adult. The brown pupa of $P$. polytes romulus is remarkably similar to that of Heraclides andraemon in shape, color, and pattern (Plate 2). However, P. demoleus also has green with yellow and pinkish-brown color forms of the pupa (Lewis 2009), which are very different from $H$. andraemon. Pupal stage lasts approximately 12 days. Twelve or more generations are possible under local citrus-growing conditions (Segarra-Carmona et al. 2010).

Adult: Adult butterflies were large and beautiful with wide wing spread. Head, thorax and legs were black with creamy yellow streaks on either side, whole abdomen. The body was covered with black and yellow hairs. Fore wings were triangular in shape while hind wings were rounded. The wings were black with yellow markings. There were two rows of parallel yellow spots along outer margins of wings and a brick red oval patch on posterior angle of the hind wing. The beautiful undersides of its wings are fully displayed as it dries its wings for the first few hours after eclosion. Antennae were black and club shaped (Plate 3). These descriptions were in agreement with the findings of Resham et al. (1986) and Maheswarababu (1988). The average length, width at middle and posterior points of male butterfly were $24.00,4.00$ and $2.50 \mathrm{~mm}$, respectively while in the female butterfly these were 25.75, 5.75 and $3.00 \mathrm{~mm}$, respectively (Table 2). These were in conformity with the findings of Resham et al. (1986) and Maheswarababu (1988). The male to female sex-ratio was 1:2.25 on sweet orange. The length and width at middle of fore wing expansion were 37.50 and $24.00 \mathrm{~mm}$, respectively while these were in hind wing expansion was 28.50 and $23.00 \mathrm{~mm}$, respectively (Table 2).

Adult longevity: The female adults lived longer than the male ones. The longevity of female and male was 6.0 to 7.0 and 3.6 to 4.2 days with an average of 6.5 and 3.9 days when provided with $10 \%$ sugar solution as a food (Table 1). The variation in adult longevity was in agreement with the findings of Singh and Gangwar (1989) who reported the longevity female and male was 5.80 and 5.10 days, respectively. 
B. Host preference under laboratory condition: The host preference of Papilio polytes romulus was documented by measuring leaf area feeding by larva in free choice test on each variety of Citrus. The per cent leaf area feeding by larva of lime swallow tail butterfly on different Citrus varieties after 24 hours of release is presented in Fig. 1 and Plate 4. The highest per cent leaf area feeding (50) was observed in BAU-3 kagoji lime which was identical to elachi lime (50) followed by orange (45), BARI kagoji lime (20), BAU-2 (20) and jamir (20) while the lowest percent leaf area feeding was in pumelo (1) followed by sweet orange (5), BAU-4 (7) and BAU-1 (10). The host preference of Papilio polytes romulus is as follows, in decreasing order was Elachi $>$ BAU-3 $>$ Orange $>$ BARI kagoji $\geq$ BAU-2 $\geq$ Jamir $>$ BAU-1 > BAU-4 > Sweet orange > Pumelo. In the present study, Papilio polytes romulus infested different citrus species and was the most prevalent and destructive pest in terms of its foliage damaging ability. Papilio polytes romulus is a major pest of the plant family Rutaceae (Atwal 1976) and can breed on all varieties of wild and cultivated citrus. In the present study 10 different varieties of citrus were evaluated as host plants. Singh and Gangwar (1989) reported that different citrus affect the growth rate of $P$. demoleus in India; they found that the G.I. value was highest in Citrus reticulata, followed by Citrus madurensis, and was least in Citrus medica. Adult longevity was highest on Citrus reticulata. Rafi et al. (1999a) reported in their field trial of 11 different Citrus species and the varieties that ovipositing wild females showed

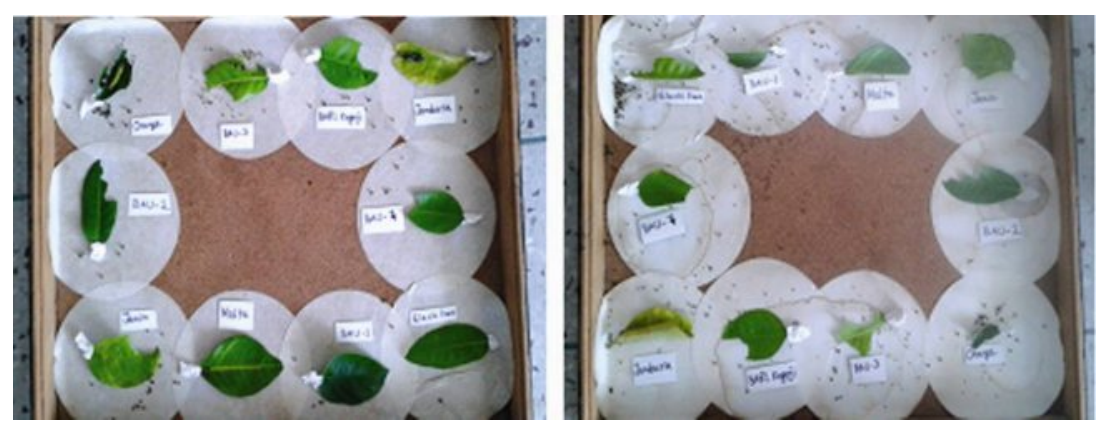

Plate 4. The leaves of different citrus varieties used as food of larvae for host preference study.

a decided preference for Citrus aurantium and Citrus reticulata. Females in this study showed similar preference for these two citrus hosts. Furthermore, in our experience, the plants with greater density of tender leaves had a higher number of eggs. Yunus and Munir (1972) showed that $P$. demoleus larvae would accept leaves of at least 19 citrus species or varieties, but demonstrated some differences in larval consumption rates, development times, and mortality between the hosts. 


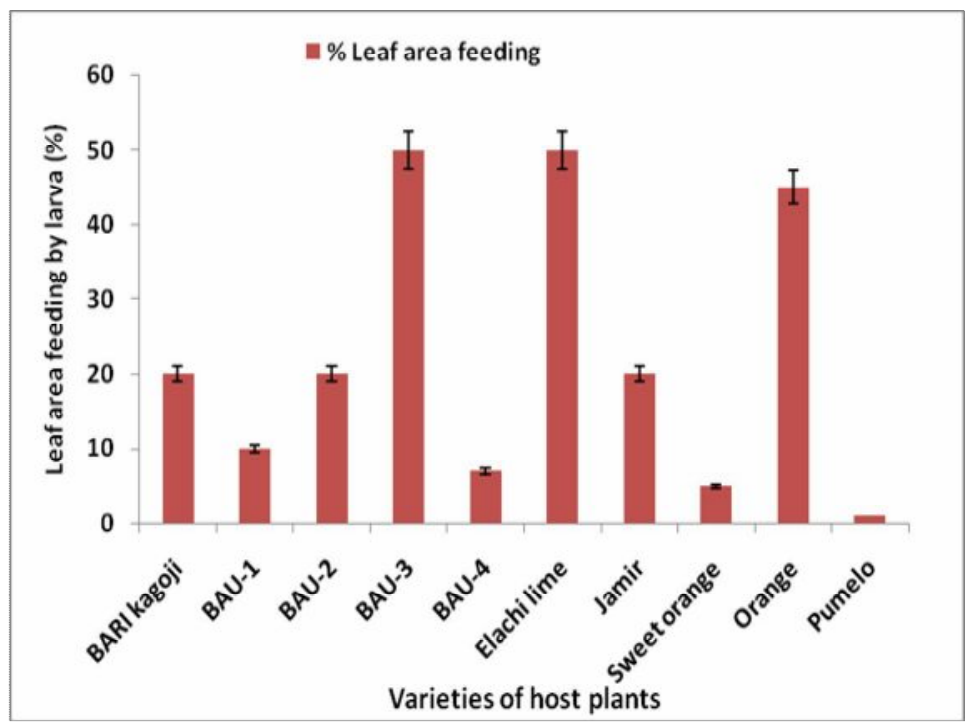

Fig 1. Host preference of lime swallow tail butterfly determined through leaf area feeding by larvae on different Citrus varieties in 24 hours after release in free choice test.

C. Leaf consumption by larvae of lime swallowtail butterfly: The percentage of leaf area consumed by different larval stages in 24, 48 and $72 \mathrm{hrs}$ after release (HAR) is presented in Fig. 2 and Plate 5. The highest percentage of leaf area was consumed by the 5th instar larva in 24 (35), 48 (42) and 72 HAR (100) followed by the 4th instar (30, 35 and 75, respectively) and the $3 \mathrm{rd}$ instar $(15,28$ and 65 , respectively) for the same period. The lowest percentage of leaf area was consumed by the 1st instar larva $(1,10$ and 15, respectively) followed by the 2nd instar (9,15 and 25, respectively) in 24, 48 and 72 HAR. From this study it was evident that the percentage of leaf area consumed increased with increasing the age of larvae. This might have caused due to the requirement of different quantity of food by its different larval stages.

It is obvious from the Fig. 2 and Plate 5 that $C$. aurantifolia leaves were generally the most preferred by the fifth instar larvae. The fifth instar larva was less selective about its food than the earlier instars because at this stage the larva needed a lot of nutrients (volume) to transform into pupa. It has been reported that $80 \%$ of food consumed during the larval stage occurs in the fifth instar. Young larvae are generally more sensitive to food quality, including nitrogen and secondary metabolites; also, the older larvae are able to feed on a wider range of host plants (Waldbauer and Friedman 1991). Although the pupal stage is non-feeding, there are massive physical transformations that occur during 


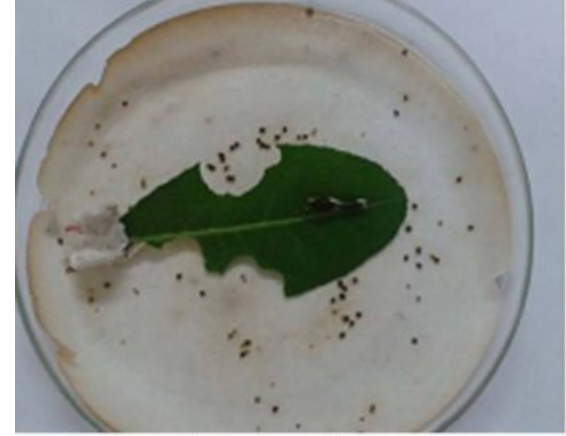

A.1st instar larva

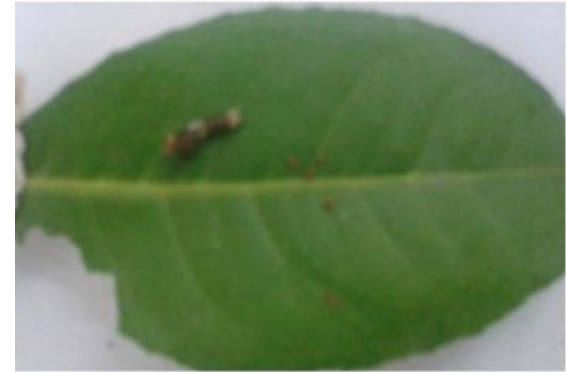

C. 2nd instar larva

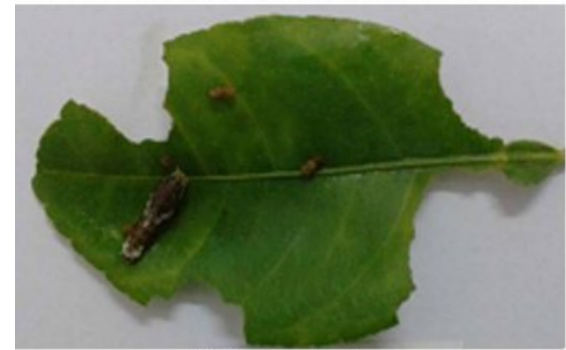

E. 3rd instar larva

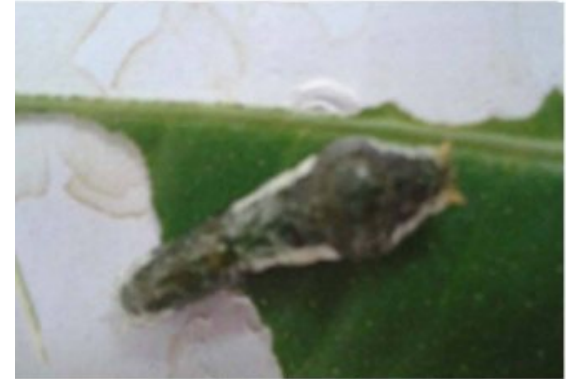

G. 4th instar larva late stage

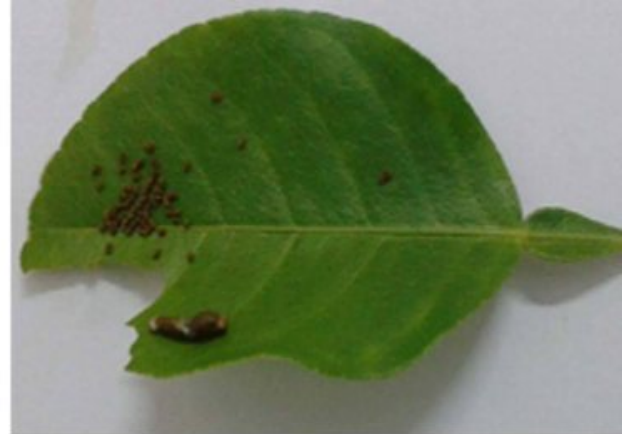

B. 2nd instar larva

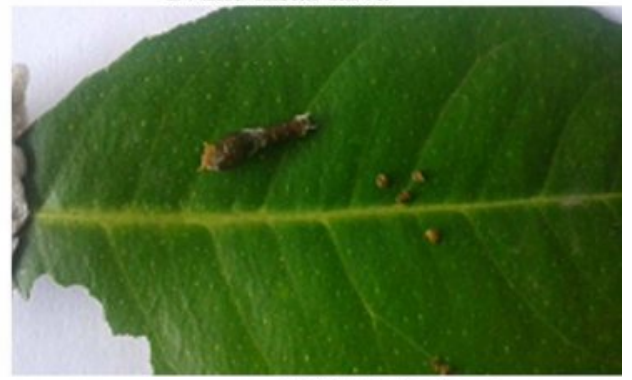

D. 3rd instar larva

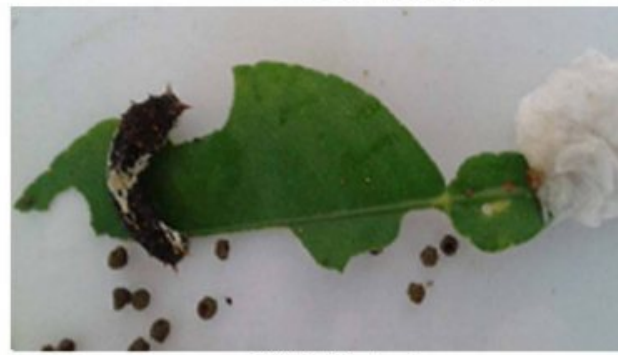

F. 4th instar larva

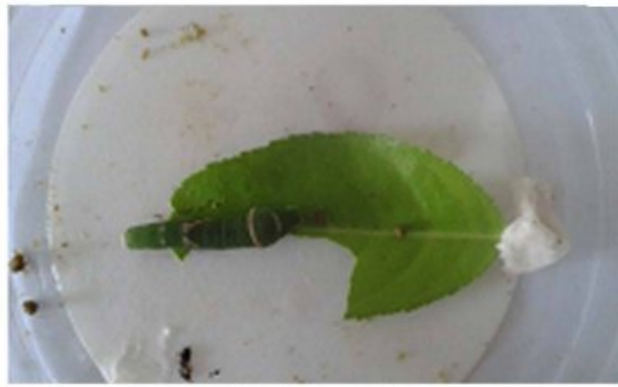

H. 5th instar larva

Plate 5 (A-H). Leaf consumption by different instar larvae of lime swallow tail butterfly. 


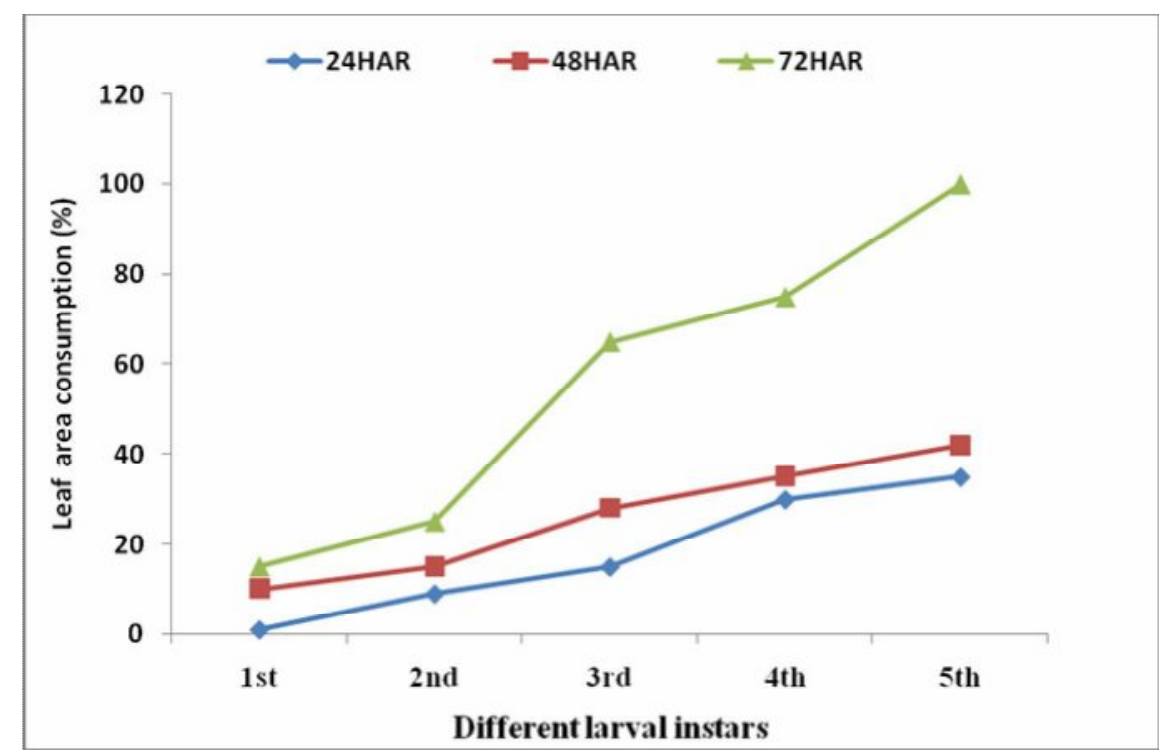

Fig. 2. The percentage of leaf area consumed by different larval instars in 24,48 and $72 \mathrm{hrs}$ after release on BAU-3 kagoji lime.

pupation. Therefore, the fifth instar larva consumes a lot of food and consequently becomes less discriminate in terms of the plants it consumed. Early instars often feed on young leaves, while later instars can also utilize mature leaves, because the young instar need to the higher nutrition for growth (Floater 1997). In addition, young larvae are more sensitive to mechanical leaf traits (e.g. toughness) owing to their smaller mouth parts and less developed musculature (Hochuli 2001). The low preference for M. koenigii leaves may have been due to their tougher texture compared to the leaves of Citrus spp. The stronger odor of the curry leaves could also be a feeding deterrent for the younger instar of $P$. polytes. The first instar always prefer young leaves which contain less of the secondary metabolites, less fiber (Cizek 2005), and toughness (Coley and Barone 1996). This is very important especially for the first instar larva because of its fragile body and poor mobility (Zalucki et al. 2002). There are three important factors, which determine the affinity of young larvae on suitable food choice. First is the provision of energy and the size of the larvae because the ability to cut through leaves depends on the size of head capsule, mass of chewing muscles and mandible morphology (Hochuli 2001). Second is the breakdown of ingested nutrient into fragments; toughness of food material may affect the end size of the food particles. Third is the absorption of food across the gut epithelium. The absorption efficiency of the digested nutrients is also positively correlated with the gut or body sizes. The later instars could move and feed on many 
parts of the plant. The fifth instar larvae for example are bigger and stronger; therefore, they feed on both young and mature leaves and on young stems. The older larvae of Cotacola spp. (Lepidoptera: Noctuidae) could consume all parts of host plants because they could move about easily (Gall 1990).

\section{References}

Asokan, R. 1997. Mass rearing and an additional instar of Papilio demoleus L. on the acid lime, Citrus aurentifolia Swingle. Insect Environ. 2(4): 128-129.

Atwal, A. S. 1964. Insect pests of citrus in the Punjab-Biology and control of citrus caterpillar Papilio demoleus L. (Lepidoptera : Papilionidae). Punjab Hort. J. 4(1): 40-44.

Atwal, A. S. 1976. Agricultural pests of India and South East Asia. Kalyani Publishers, New Delhi, India. 479 pp.

Badawi, A. 1981. Studies on some aspects of the biology and ecology of the citrus butterfly Papilio demoleus L. in Saudi Arabia (Papilionidae, Lepidoptera). Zeit. Angew. Entomol., 91(3): 286292.

BBS. 2016. Bangladesh Bureau of Statistics, Yearbook of Agricultural Statistics-2015, $27^{\text {th }}$ Series, Statistics and Information Division, Ministry of Planning, Government of the People's Republic of Bangladesh.

Butani, D. K. 1973. Insect pests of fruit crops- citrus. Pesticides. 7(12): 23-26.

Butani, D. K. 1979. Insects and fruits. Indian Agriculturul Research Institute, New Delhi. India.

Butani, D. K. and Jotwani, M. G. 1975. Trends in the control of insect pests of fruit crops in India. Pesticides Mannual: 139-149.

Chadha, K. L. 1970. Rootstocks in citrus decline in India - causes and control (Chadha, K. L., Randhawa, N. S., Bindra, G. S., Chohan, J. S. and Knoor, L. C. eds.) A joint publication of Punjab Agril. University, Ohio State University and USAID. pp. 9-25.

Cížek, L. 2005. Diet composition and body size in insect herbivores: Why do small species prefer young leaves?. European J. Entomol. 102: 675-681.

Coley, P. D. and Barone, J. A. 1996. Herbivory and plant defenses in tropical forests. Ann.l Rev. Eco. System 27: 305-335.

Corbet, A. S. and Pendlebury, H. M. 1992. The Butterflies of the Malay Peninsula. 4th edn. Kuala Lumpur, Malaysia: United Selangor Press.

Ebeling, W. 1959. Sub-tropical Fruits Pests. University of California Press, Los Angeles. 287 p.

Floater, G. J. 1997, Rainfall, nitrogen and host plant condition: Consequences for theprocessionary caterpillar, Ochrogaster lunifer. Eco. Entomol. 22: 3247-255.

Gall, L. F. 1990, Evolutionary ecology of sympatric Catocala moths (Lepidoptera: Noctuidae) I. Experiments on larval food plant specificity. J. Res. on the Lepidoptera. 29: 173-194

Ganguli, R. N. and Ghosh, M. R. 1967. Biology of Papilio demoleus pest of citrus in Tripura state. Indian Agricul. 11:13-18.

Hochuli, D. F. 2001, Insect herbivore and ontogeny: How do the growth and development influence feeding behaviour, morphology and host use?. Austral. Ecology 26: 563-570.

Lakshminarayanamma. 2000. Studies on seasonal occurrence, biology and control of citrus butterfly, P. demoleus Linnaeus (Papilionidae : Lepidoptera) M.Sc (Ag.) thesis submitted to Acharya NG Ranga Agricultural University, Hyderabad. pp 141.

Leslie, A. J. and Berenbaum, M. R. 1990. Role of the osmeterial gland in swallowtail larvae (Papilionidae) in defense against an avian predator. J. - Lepidopterists' Soc. 44(4): 245-251. 
Development, host preference and leaf consumption

Lewis, D. S. 2009. Papilio demoleus Linnaeus. IFAS Featured Creatures. Department of Entomology and Nematology, University of Florida. http://entnemdept.ufl.edu/creatures/ bfly/lime_swallowtail.htm\#dist. Last accessed December 2013.

Maheswarababu, P. 1988. Biology and chemical control of citrus butterfly P. demoleus Linnaeus (Papilionidae : Lepidoptera) M.Sc (Ag.) Thesis submitted to Andhra Pradesh Agricultural University, Hyderabad. pp. 117.

Mishra, S. C. and Pandey, N. D. 1965. Some observations on the biology of Papilio demoleus Linn. (Papilionidae, Lepidoptera). Labdev. J. Sci. Technol. 3: 142-143.

Mushtaque, M. 1964. Studies on the biology and history of lemon butterfly, Papilio demoleus Linn. M.S. Thesis, Sindh Agriculture University, Tandojam, Sindh, Pakistan, 66 pp.

Pruthi, H. 1969. Text book of Agriculturla Entomology. Ind. Council of Agril. Res., New Delhi pp:634.

Radke, S. G. and Kandalkar, H. G. 1988. Observations on the lemon butterfly, Papilio demoleus Linnaeous (Lepidoptera: Papilionidae) PKV Res. J. 13(2):176-177.

Rafi, M. A., M. A. Matin and S. A. Saghir. 1989. Studies on some bio-ecological aspects of the citrus butterfly Papilio demoleus L. (Lepidoptera: Papilionidae) in the Barani ecology of Pakistan. Pakistan. J. Sci. and Ind. Res. 32(1): 36-38.

Rafi, M. A., M. R. Khan and M. Ilyas. 1999a. Host preference of lemon butterfly Papilio demoleus L. in the Northern Barani areas of Pakistan. Pakistan J. Sci. 51(3-4): 93-94.

Rafi M. A., M. A. Matin and M. R. Khan. 1999b. Number of generations and their duration of Lemon Butterfly (Papilio demoleus L.) in rainfed ecology of Pakistan. Pakistan. J. Sci. Res. 51(3-4): 131-136.

Resham, B. T., Fanindra, P. N. and Butani, D. K. 1986. Insect pests of citrus in Nepal and their control. Pestology. 10(4): 24-27.

Samson, J. A. 1986. Tropical fruits. $2^{\text {nd }}$ ed. Longman, 4 p.

Segarra-Carmona, A. E., Cabrera-Asencio, I., Flores-López, L. E. and Morales-Collado, L. 2010. Life cycle and control of the Asian lime swallow tail, Papilio demoleus (Lepidoptera: Papilionidae): A new invasive pest in Puerto Rico. J. Agr. U. Puerto Rico. 94(1/2): 165-174.

Sharifi, S. and Zarea, N. 1970. Biology of Citrus butterfly Papilio demoleus (Lepidoptera: Papilionidae) Ann. Ent. Soc., Amer. 63(5):1211-1213.

Singh, Y. P. and S. K. Gangwar. 1989. Biology of the lemon butterfly (Papilio demoleus L.) on Khasi mandarin and its development on citrus cultivars. J. Andaman Science Assoc. 5(2): 151-153.

Talbot, G. 1939. The Fauna of British India, Butterflies, Vol. 1. (Covers Papilionidae and Pieridae). Today and Tomorrow Printers and Publishers, New Delhi, India. 600 pp.

Tauber, C. A., Tauber, M. J. and Masaki, S. 1986. Seasonal adaptations of insects. New York, Oxford University Press. 411 p.

Waldbauer, G. P. and Friedman, S. 1991. Self-selection of optimal diets by insects. Annu. Rev. Entomol. 36: 43-63.

Younus, M. and Munir, M. 1972. Host plants and host preference of lemon butterfly, Papilio demoleus linn. caterpillars. Pakistan J. Zool. 4(2): 213-232.

Zalucki, M. P., Clarke, A. R. and Malcolm, S. B. 2002, Ecology and behaviour of first instar larval Lepidoptera. Annu. Rev. Entomol. 47: 361-393.

(Revised copy received on 21.01.2019) 